RSC Adv., 2015,5, 84523-84525

DOI: $10.1039 / \mathrm{C} 5 \mathrm{RA} 14546 \mathrm{E}$ 


\title{
Orosomucoid binding induced amplification of the inherent chirality of the immunosuppressant drug sirolimus
}

\author{
Ferenc Zsila* \\ Research Group of Chemical Biology, Institute of Organic Chemistry, \\ Research Centre for Natural Sciences, Hungarian Academy of Sciences, POB 289, \\ H-1519, Budapest, Hungary
}

Corresponding author: Ferenc Zsila

POB 289, H-1519, Budapest, Hungary

Email: zsila.ferenc@tttk.mta.hu 


\begin{abstract}
Circular dichroism (CD) spectroscopic data indicate the conformational change of the triene moiety of the immunosuppressive agent sirolimus (rapamycin) upon its binding to human $\alpha_{1}$ acid glycoprotein (orosomucoid). The development of an intense, negative $\pi \rightarrow \pi^{*} \mathrm{CD}$ Cotton effect and the bathochromic shift of the corresponding UV band are attributed to the increased helical distortion of the conjugated $\pi$-system. Comparative chiroptical evaluation of the interaction of sirolimus with the separated genetic variants of orosomucoid indicates that the F1/S form is dominant in the amplification of the inherent chirality of the triene chromophore while the A variant induces much weaker structural modification. Consistently, the drug binding affinities of the native protein and the F1/S variant estimated from the CD spectra are close to each other $\left(\sim 2 \times 10^{5} \mathrm{M}^{-1}\right)$.
\end{abstract}

Keywords: $\quad \alpha_{1}$-acid glycoprotein; circular dichroism; conformational change; helical distortion; orosomucoid; rapamycin; sirolimus; triene

Abbreviations: AAG, $\alpha_{1}$ acid glycoprotein; CD, circular dichroism; CE, Cotton effect 
$\alpha_{1}$-Acid glycoprotein (AAG), also named orosomucoid, is an abundant acute phase component of the human plasma, the exact biological function of which remains to be elucidated. ${ }^{1,2}$ Its anti-inflammatory and immunosuppressive activity are well documented including the inhibition of neutrophil activation, lymphocyte proliferation, platelet aggregation and a variety of other immune functions. ${ }^{3,4}$ As a member of the lipocalin family, the single polypeptide chain of AAG folds into a $\beta$-barrel structure enclosing a wide, central cavity where a broad array of organic compounds can be bound. ${ }^{5,6}$ Macrolide antibiotics are typical AAG binding agents ${ }^{7-9}$ possessing a large macrocycle which is reminiscent to that of the potent immunosuppressive drug sirolimus (rapamycin). Sirolimus is a chiral, multichromophoric antifungal compound of bacterial origin consisting of triene, lactone, lactol, enone, and ketone moieties (Scheme 1). ${ }^{10,11}$ The circular dichroism (CD) activity of the lactone and enone groups are displayed below $250 \mathrm{~nm}$. The asymmetrically perturbed $\mathrm{n} \rightarrow \pi^{*}$ transitions of the 9-, 26-, and 32-ones give rise to a negative CD band centered around $300 \mathrm{~nm}$ (Fig. 1). ${ }^{12}$ The weak, $\pi \rightarrow \pi^{*}$ of origin contribution of the triene moiety is suppressed by the more intense carbonyl Cotton effects (CEs) and can only be seen as unresolved vibrational peaks on the short-wavelength side of the $n \rightarrow \pi^{*}$ feature. ${ }^{12}$ The presence of the AAG in the sample solution, however, deeply alters this chiroptical profile amplifying the CD amplitudes in the absorption region of the triene chromophore (Fig. 1). The molar dichroic absorption coefficient $(\Delta \varepsilon)$ measured in protein-free buffer solution at $275 \mathrm{~nm}$ increases by ten-fold and the anisotropy factor $(g=\Delta \varepsilon / \varepsilon)$ between $260-280 \mathrm{~nm}$ raises also by an order of magnitude $\left(\sim 10^{-4} \rightarrow \sim 10^{-3}\right)$. Concomitantly, the $g_{\max }$ value of the $\mathrm{n} \rightarrow \pi^{*} \mathrm{CE}$ is bathochromically shifted by $5 \mathrm{~nm}$ (Fig. 2). The excitation energy of $n \rightarrow \pi^{*}$ transition of the carbonyl chromophore sensitively depends on the polarity of the medium. ${ }^{13,14}$ The decrease of solvent polarity shifts it to longer wavelengths and vice versa. The blue shift exhibited in polar solvents is ascribed chiefly to hydrogen bonding between the $>\mathrm{C}=\mathrm{O}$ group and the 
solvent molecules with smaller contributions from a general dielectric effect. Therefore, the observed red shift is consistent with change of the highly polar and protic aqueous environment around some carbonyl groups of sirolimus to the less polar, hydrophobic binding site of AAG.

Similarly to the allied UV peak, the induced $\pi \rightarrow \pi^{*}$ CE shows a characteristic vibrational progression. All of these changes attest that upon binding to AAG, the triene unit of sirolimus undergoes a significant conformational rearrangement. The overall helicity of the conjugated $\pi$-system strongly rises in AAG bound state that may occur by twisting around either $\mathrm{C}-\mathrm{C}$ single or $\mathrm{C}=\mathrm{C}$ double bonds with concomitant blue or red shift of the corresponding absorption band, respectively. The red shift observed in the present case (Fig. 1) suggests that the torsional deformation of the polyene chain required to fit the molecule to the protein binding site occurs by a rotation around the $\mathrm{C}=\mathrm{C}$ double bonds. ${ }^{15,}{ }^{16}$ Another possible source of the UV red shift of the triene moiety could be the replacement of the bulk aqueous phase by the apolar protein binding milieu. Decreasing of the solvent polarity, however, hardly affects the UV maxima of sirolimus (see inset in Fig. 1) suggesting that this effect is unimportant. Finally, the AAG binding induced helical distortion of the triene moiety is also supported by the less resolved vibrational peaks of the UV band of drug-protein complexes (Fig. 1) since enhancement of the vibrational fine structure is associated with planarization of the polyene systems. ${ }^{12}$

The binding of sirolimus to its the pharmacological target protein named FKBP is also accompanied with some modest CD and UV spectroscopic changes that refer to a more planar and rigid conformation of the triene moiety adopted at the binding site. ${ }^{12}$

It is to be noted that the related immunosuppressive drug tacrolimus lacks the triene component. Despite of its AAG association, ${ }^{17}$ the intrinsic $n \rightarrow \pi^{*} \mathrm{CE}$ of tacrolimus shows no alteration in protein solution (Fig. S1, ESI) pointing out the importance of the triene chromophore in the CD spectroscopic detection of the binding interaction. 
Commercial AAG samples prepared from normal pooled serum consist of two main genetic variants called $\mathrm{F} 1 / \mathrm{S}$ and $\mathrm{A}$ in a ratio of $70: 30 .{ }^{18,19}$ Due to sequence alterations (22 residues), the drug binding cavity of the variants differs from each other. ${ }^{6}$ The wide, crevice-like pocket of the F1/S form is divided into three sub-chambers while the narrower cavity of the A variant consists only of two ones that accounts for their well documented distinct ligand binding properties. $^{20-22}$ Therefore, the interaction of sirolimus with the separated genetic variants of AAG has also been studied. The F1/S variant induced very similar CD changes and UV shift as seen with the native sample (Fig. 3). In marked contrast, the A form caused a much smaller intensity gain of the $\pi \rightarrow \pi^{*} \mathrm{CE}$ and only a minor red shift of the absorption maxima. Accordingly, F1/S binding plays a decisive contribution in the modification of the CD and UV spectroscopic profile of sirolimus. In relation to the A variant, entrapment of the drug molecule in the binding crevice of the F1/S form results in a significantly larger helical twist of the triene moiety.

The CD curve of free sirolimus molecules displays a zero cross-over point around $270 \mathrm{~nm}$ but AAG binding produces non-zero, negative values in that region. Thus, the ellipticity data recorded at $270 \mathrm{~nm}$ during the titration of AAG solution with sirolimus can be used to estimate the binding affinity constant. Non-linear regression analysis yielded very similar $K_{\mathrm{a}}$ values $\left(\sim 2 \times 10^{5} \mathrm{M}^{-1}\right)$ for the native protein as well as the F1/S variant (Fig. S2, ESI). The markedly smaller value than that of 1 obtained for $n$ in the case of the native sample (the mixture of the genetic variants) might refer to the non-specific binding contribution of the A form.

Overall, it is shown for the first time that the conformational chirality of the triene chromophore allows the chiroptical sensing and evaluation of sirolimus-AAG interactions providing a basis to use this methodology for studying related compounds, too (e.g., temsirolimus, everolimus, ridaforolimus). 


\section{Acknowledgement}

Separation of the AAG genetic variants was made by my late colleague, Dr. György Mády.

Electronic supplementary information (ESI) available: Experimental procedures and further spectroscopic data. 


\section{References}

1 Z. Luo, H. Lei, Y. Sun, X. Liu and D. F. Su, J. Physiol. Biochem., 2015, 71, 329-340.

2 Z. H. Israili and P. G. Dayton, Drug Metab. Rev., 2001, 33, 161-235.

3 C. Gemelli, A. Martello, M. Montanari, T. Zanocco Marani, V. Salsi, V. Zappavigna, S. Parenti, T. Vignudelli, T. Selmi, S. Ferrari and A. Grande, Exp. Cell Res., 2013, 319, 3201-3213.

4 T. Hochepied, F. G. Berger, H. Baumann and C. Libert, Cytokine Growth Factor Rev., 2003, 14, 25-34.

5 D. R. Schönfeld, R. B. G. Ravelli, U. Mueller and A. Skerra, J. Mol. Biol., 2008, 384, 393-405.

6 K. Nishi, T. Ono, T. Nakamura, N. Fukunaga, M. Izumi, H. Watanabe, A. Suenaga, T. Maruyama, Y. Yamagata, S. Curry and M. Otagiri, J. Biol. Chem., 2011, 286, $14427-$ 14434.

7 G. A. Dette and H. Knothe, Biochem. Pharmacol., 1986, 35, 959-966.

8 G. A. Dette, H. Knothe and G. Koulen, Drugs Exp. Clin. Res., 1987, 13, 567-576.

9 C. B. Gambacorti-Passerini, F. Rossi, M. Verga, H. Ruchatz, R. Gunby, R. Frapolli, M. Zucchetti, L. Scapozza, S. Bungaro, L. Tornaghi, F. Rossi, P. Pioltelli, E. Pogliani, M. D'Incalci and G. Corneo, Blood Cells Mol. Dis., 2002, 28, 361-372.

10 K. L. Napoli and P. J. Taylor, Ther. Drug Monit., 2001, 23, 559-586.

11 J. Liang, J. Choi and J. Clardy, Acta Cryst. D, 1999, 55, 736-744.

12 Y. Chen, P. Zhou, N. Berova, H. Zhang, K. Nakanishi, A. Failli, R. J. Steffan, K. Molnar-Kimber and T. J. Caggiano, J. Am. Chem. Soc., 1994, 116, 2683-2684.

13 W. P. Hayes and C. J. Timmons, Spectrochim. Acta, 1965, 21, 529-541.

14 G. P. Powell, R. N. Totty and J. Hudec, J. Chem. Soc., Perkin Trans. 1, 1975, 10151019.

15 E. Tajkhorshid, J. Baudry, K. Schulten and S. Suhai, Biophys. J., 2000, 78, 683-693.

16 R. Rajamani, Y. L. Lin and J. Gao, J. Comput. Chem., 2011, 32, 854-865.

17 R. Venkataramanan, A. Swaminathan, T. Prasad, A. Jain, S. Zuckerman, V. Warty, J. McMichael, J. Lever, G. Burckart and T. Starzl, Clin. Pharmacokinet., 1995, 29, 404430.

18 I. Yuasa, K. Umetsu, U. Vogt, H. Nakamura, E. Nanba, N. Tamaki and Y. Irizawa, Hum. Genet., 1997, 99, 393-398. 
19 F. Hervé, E. Gomas, J. C. Duche and J. P. Tillement, J. Chromatogr., 1993, 615, 4757.

20 I. Fitos, J. Visy, M. Simonyi, G. Mády and F. Zsila, Biochim. Biophys. Acta, 2010, 1800, 367-372.

21 I. Fitos, J. Visy, F. Zsila, Z. Bikádi, G. Mády and M. Simonyi, Biochem. Pharmacol,, 2004, 67, 679-688.

22 I. Fitos, J. Visy, F. Zsila, G. Mády and M. Simonyi, Biochim. Biophys. Acta, 2006, 1760, 1704-1712. 


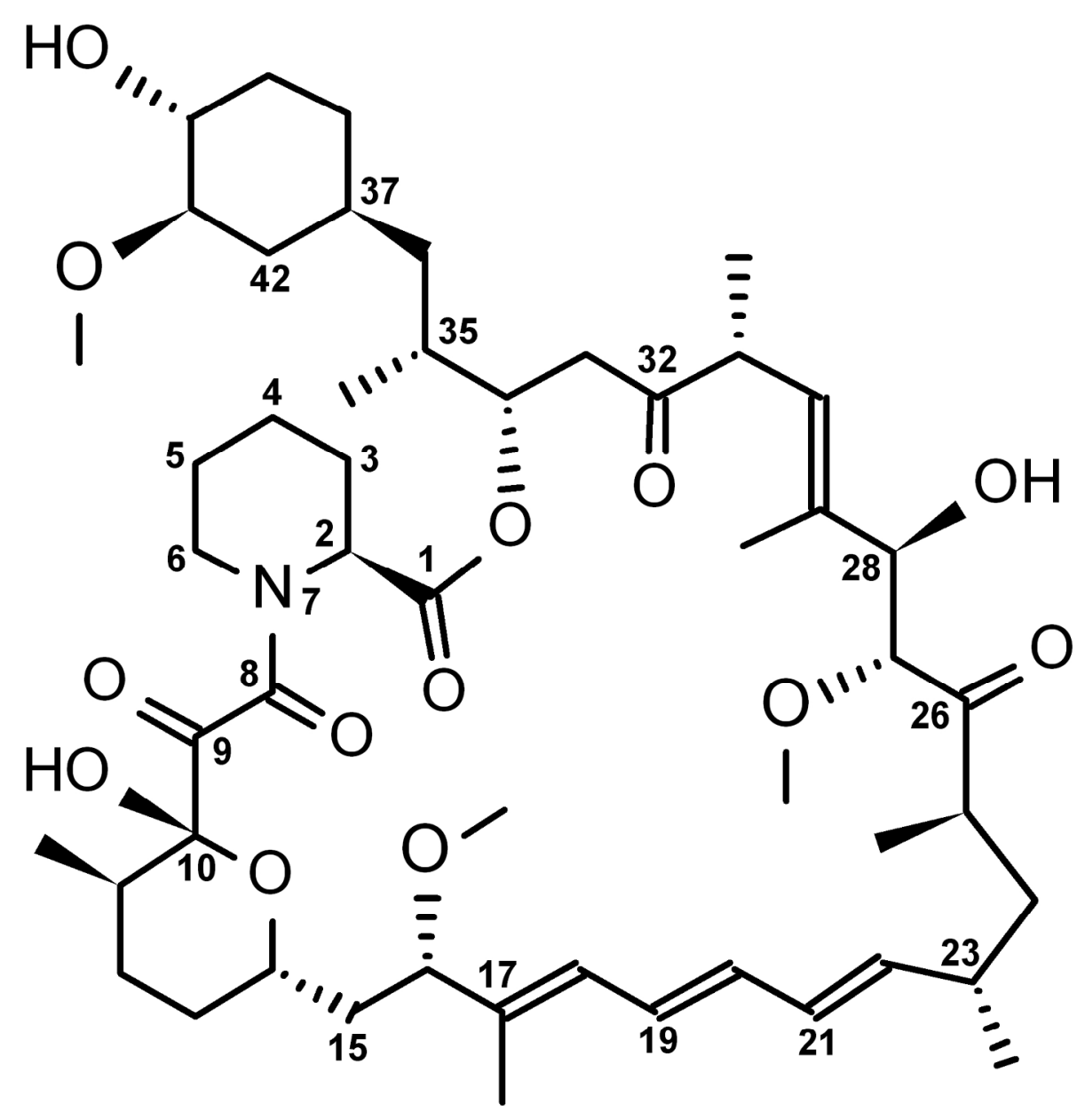

Scheme 1

Chemical structure of sirolimus (rapamycin). $756 \times 754 \mathrm{~mm}$ (72 x 72 DPI) 

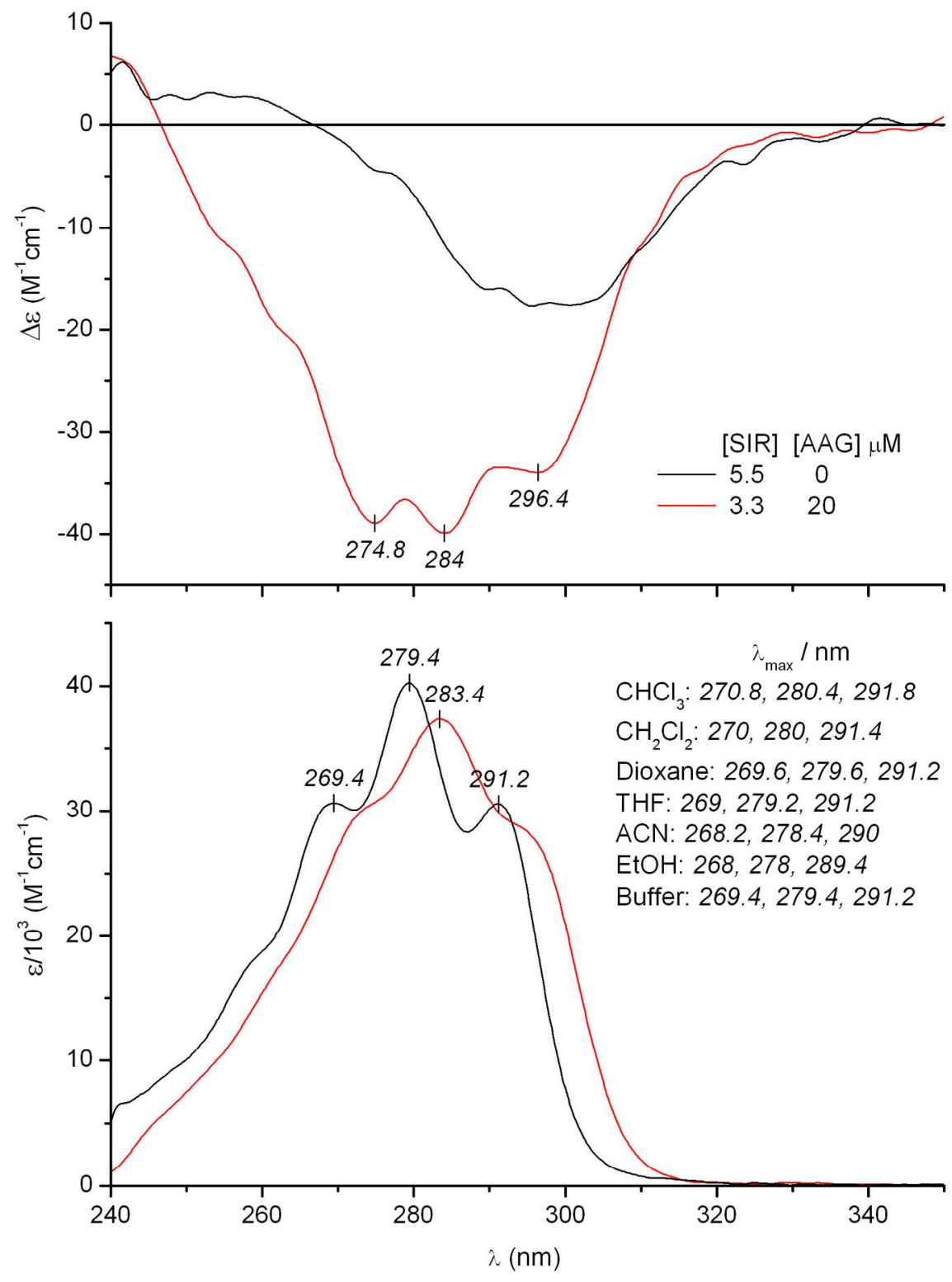

Figure 1

Difference CD and UV absorption spectra of sirolimus in the absence and in the presence of native AAG ( $\mathrm{pH}$ 7.4 Ringer buffer, $25^{\circ} \mathrm{C}$ ). Inset shows the absorption maxima of the drug measured in various solvents (THF, tetrahydrofuran; ACN, acetonitrile; $\mathrm{EtOH}$, ethanol). $663 \times 878 \mathrm{~mm}(72 \times 72 \mathrm{DPI})$ 


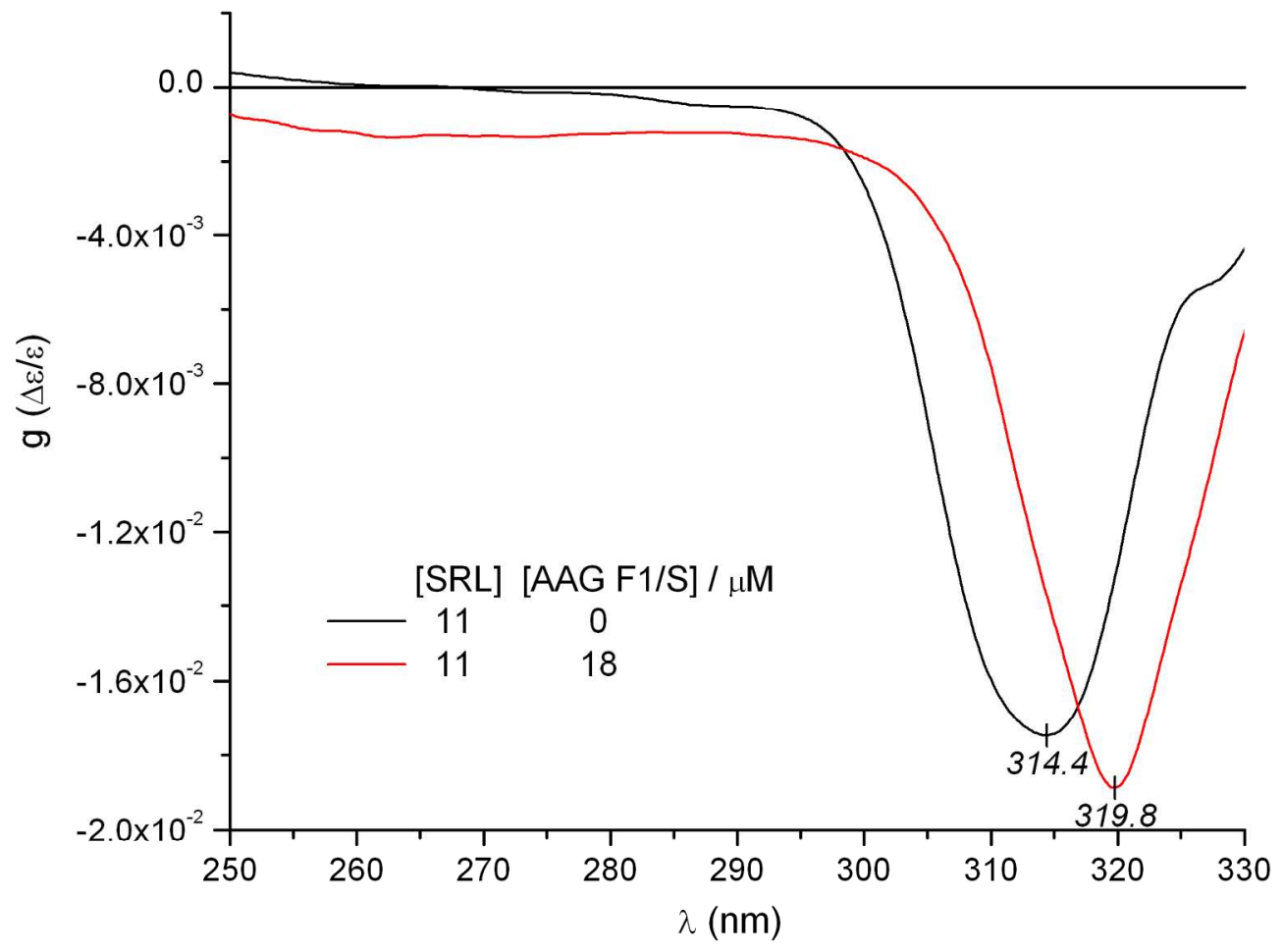

Figure 2

The anisotropy factor ( $\mathrm{g}$ value) of sirolimus (SRL) calculated in the absence and in the presence of the F1/S genetic variant of AAG.

$762 \times 580 \mathrm{~mm}(72 \times 72$ DPI $)$ 

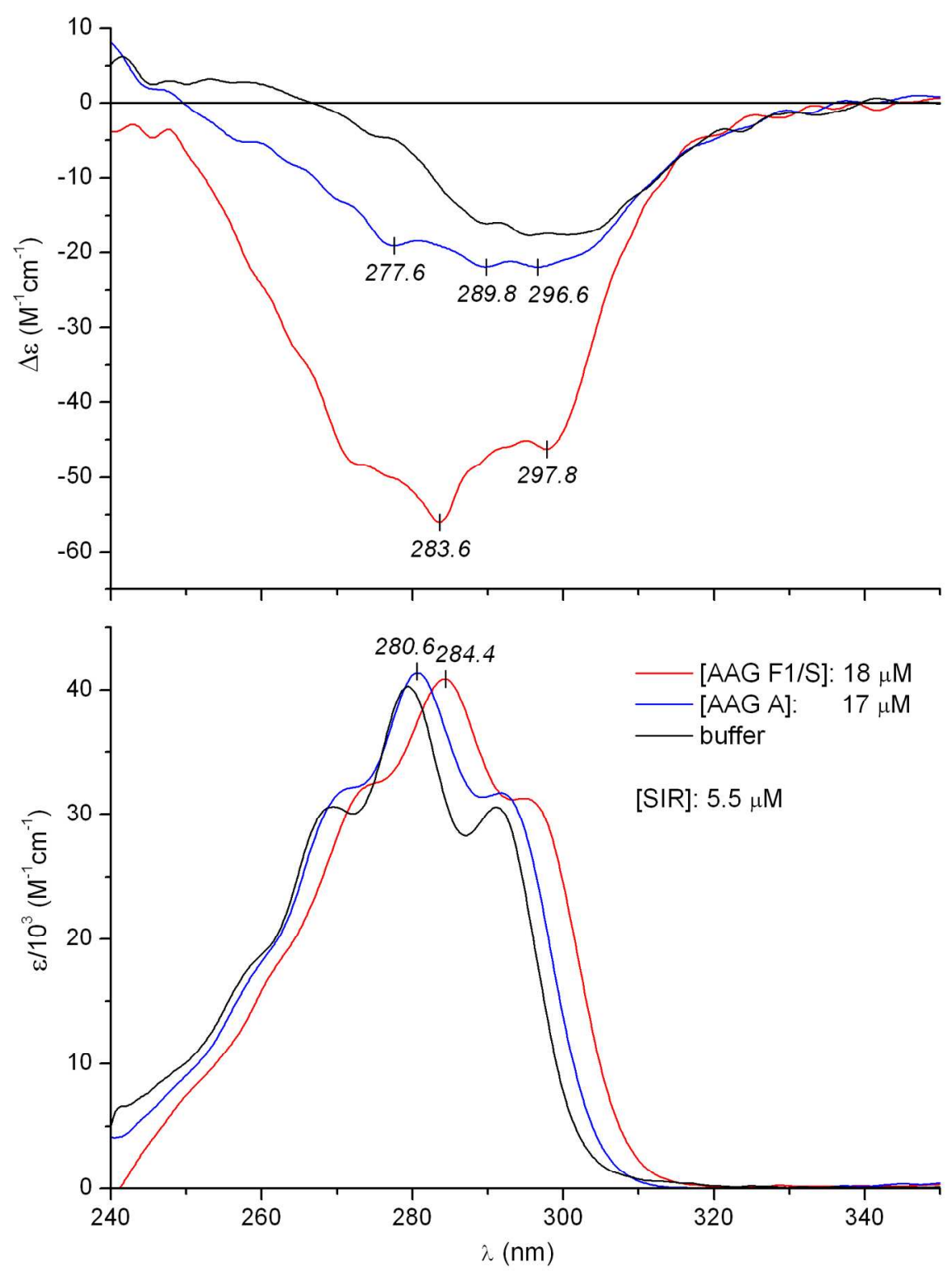

Figure 3

Comparison of the CD and UV spectroscopic changes of sirolimus induced by the F1/S and $A$ genetic variants of AAG ( $\mathrm{pH} 7.4$ Ringer buffer, $\left.25^{\circ} \mathrm{C}\right)$. $635 \times 839 \mathrm{~mm}(72 \times 72 \mathrm{DPI})$ 
Supplementary Information 


\section{Materials and methods}

\section{Materials}

Native AAG (Sigma, cat\# G9885, lot\# 018K7535), sirolimus (LC Laboratories, cat\# R-5000, lot\# ASW-112), and tacrolimus (LC Laboratories, cat\# F-4900, lot\# ATH-109) were used as supplied. The F1/S and A genetic variants of AAG were separated following the method of Hervé et al. ${ }^{1}$ as described previously. ${ }^{2}$ The molar ratio of the F1/S:A genetic variants in the commercial native AAG mixture was 75:25.

\section{Preparation of drug and $A A G$ solutions}

Stock solutions of sirolimus and tacrolimus were prepared freshly in HPLC grade ethanol. The volume of ethanol added into AAG solutions never exceeded 3\% (v/v) and caused negligible effects on the protein CD spectrum. AAG was dissolved in physiological Ringer buffer, pH $7.4\left(8.1 \mathrm{mM} \mathrm{Na}_{2} \mathrm{HPO}_{4} \cdot 12 \mathrm{H}_{2} \mathrm{O}, 1.5 \mathrm{mM} \mathrm{KH} \mathrm{PO}_{4}, 137 \mathrm{mM} \mathrm{NaCl}, 2.7 \mathrm{mM} \mathrm{KCl}, 0.8\right.$ $\mathrm{mM} \mathrm{CaCl} 2,1.1 \mathrm{mM} \mathrm{MgCl}_{2}$ ). AAG concentration was calculated for a molecular mass of 40,000

\section{Circular dichroism and UV absorption spectroscopic measurements}

CD and UV absorption spectra were recorded on a JASCO J-715 spectropolarimeter at $25 \pm$ $0.2{ }^{\circ} \mathrm{C}$ in a rectangular quartz cell of $1 \mathrm{~cm}$ optical path length (Hellma, USA). Temperature control was provided by a Peltier thermostat equipped with magnetic stirring. Each spectrum represents the average of three scans obtained by collecting data at a scan speed of 100 $\mathrm{nm} / \mathrm{min}$. Absorption spectra were obtained by conversion of the high voltage (HT) values of the photomultiplier tube of the $\mathrm{CD}$ equipment into absorbance units. $\mathrm{CD}$ and UV curves of drug-AAG mixtures were corrected by blank protein solution. JASCO CD spectropolarimeters record data as ellipticity (' $\Theta$ ') in units of millidegrees (mdeg). The 


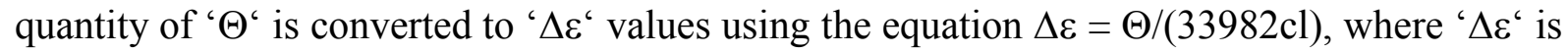
the molar circular dichroic absorption coefficient expressed in $\mathrm{M}^{-1} \mathrm{~cm}^{-1}$, ' $\mathrm{c}$ ' is the molar concentration of the ligand ( $\mathrm{mol} / \mathrm{L}$ ), and ' $\mathrm{l}$ ' is the optical pathlength expressed in $\mathrm{cm}$.

\section{Calculation of the AAG binding parameters of sirolimus}

The stoichiometry of sirolimus-AAG complexes was determined by linear regression analysis of the linear parts of the $\mathrm{CD}$ titration curves. Intersection of linear extrapolations of the first and plateau phase of the titration data provides the number of binding sites $(n)$ per a protein molecule (Fig. S2, ESI). The obtained values were taken into account in calculation of the association constants.

Drug-Protein binding can be quantified by the association constant $\left(K_{a}\right)$ :

$$
\mathrm{D}+\mathrm{P} \rightleftharpoons \mathrm{DP} ; \quad K_{a}=\frac{[D P]}{[D][P]}
$$

It is evident that

$$
\begin{gathered}
{[\mathrm{D}]=c_{\mathrm{d}}-[\mathrm{DP}]} \\
\text { and } \\
{[\mathrm{P}]=c_{\mathrm{P}}-[\mathrm{DP}]}
\end{gathered}
$$

where $c_{d}$ and $c_{p}$ are the total molar concentrations of the drug and the protein, respectively.

Since the formation of sirolimus-AAG complexes is responsible for the ICD signal measured at $270 \mathrm{~nm}$, it can be written that

$$
I C D(m d e g)=k[\mathrm{DP}]
$$

where $k$ is a constant. Using equations $1-4$, we obtain

$$
I C D(m \mathrm{deg})=\frac{k}{2}\left(c_{p}+c_{d}+K_{a}^{-1}-\sqrt{\left(c_{p}+c_{d}+K_{a}^{-1}\right)^{2}-4 c_{p} c_{d}}\right)
$$

Non-linear regression analysis of the ICD values using NLREG ${ }^{\circledR}$ (statistical analysis program, ver. 3.4) was performed to obtain the value of $K_{a}$. 


\section{References}

1. F. Hervé, E. Gomas, J. C. Duche and J. P. Tillement, J. Chromatogr., 1993, 615, 4757.

2. I. Fitos, J. Visy, F. Zsila, Z. Bikádi, G. Mády and M. Simonyi, Biochem. Pharmacol., 2004, 67, 679-688. 


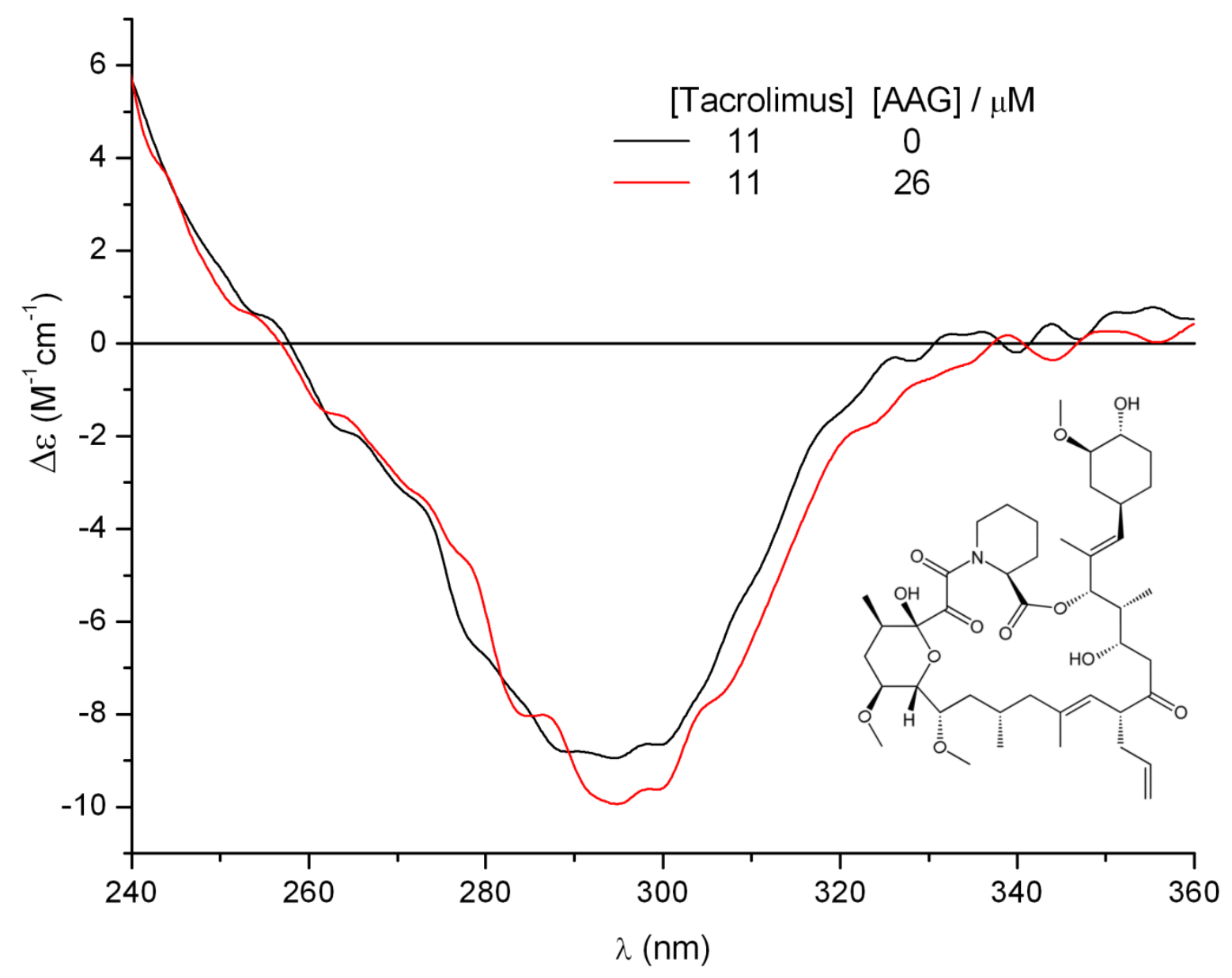

\section{Supplementary Figure 1}

Comparison of CD spectra of tacrolimus measured in the absence and presence of native AAG (mixture of the genetic variants). Inset shows the chemical structure of the drug. 


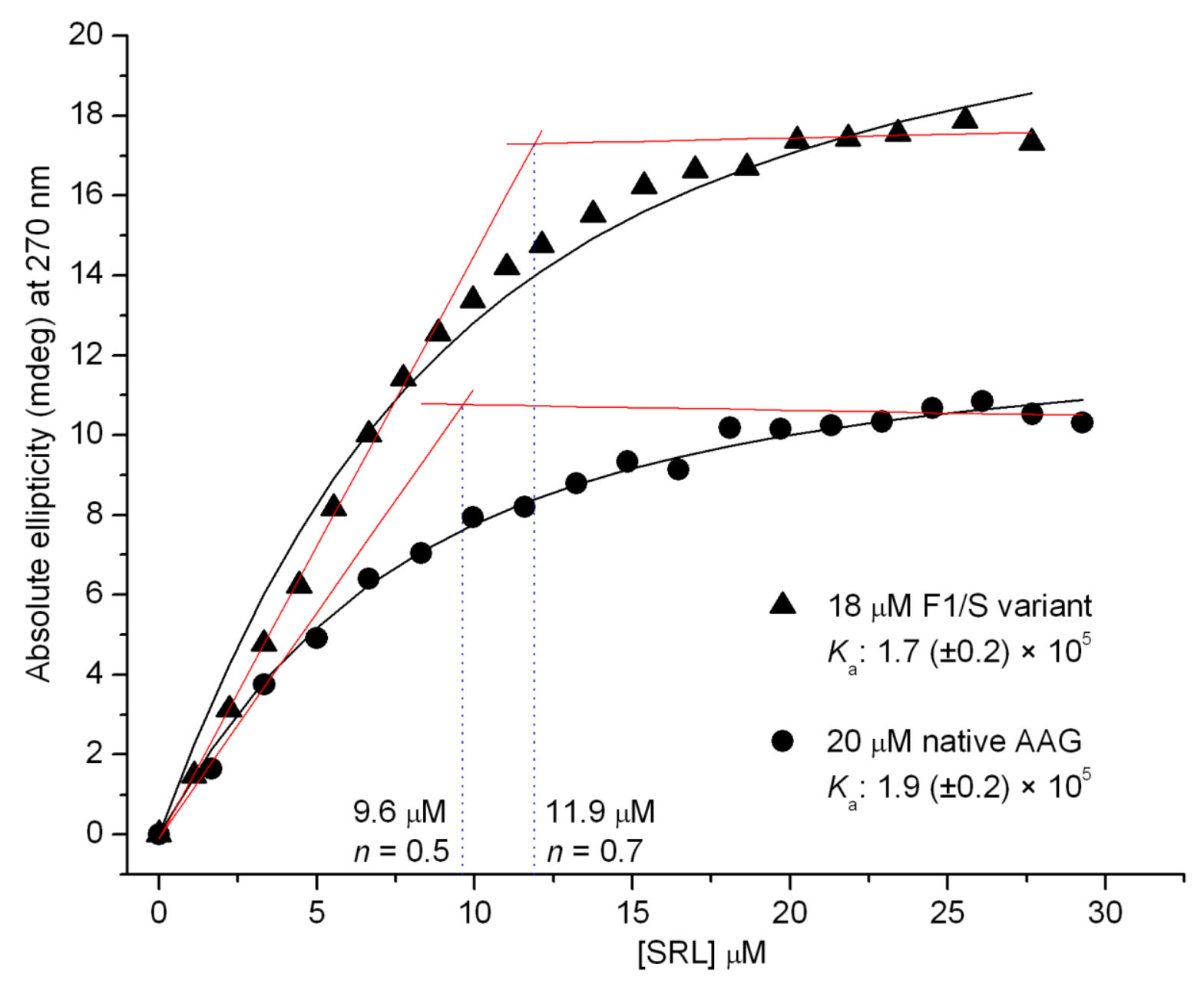

\section{Supplementary Figure 2}

Non-linear regression analysis of the ellipticity changes of sirolimus obtained by titration of AAG solutions (solid lines are the results of curve fitting procedures). Association constants $\left(K_{\mathrm{a}}\right)$ estimated for the native protein and the F1/S genetic variant are shown. The number of the binding sites per a protein molecule $(n)$ was estimated by linear regression analysis of the linear parts of the CD titration curves (red lines). 